\title{
Diagnostic Value of Oral Prednisolone Test for Chronic Obstructive Pulmonary Disorders
}

Berna D. L. Broekbuizen, $M D, P b D^{1}$

Alfred P. E. Sachs, MD, $P b D^{1}$

Karel G. M. Moons, PbD ${ }^{1}$

Samir A. A. Cheragwandi, $M D^{2}$

Hendrik E. J. Sinninghe Damsté, $M D^{3}$

Giel J. A. Wijnands, $M D, P b D^{4}$

Theo J. M. Verbeij, MD, $P b D^{1}$

Arno W. Hoes, MD, PbD

'University Medical Center Utrecht, Julius Center for Health Sciences and Primary

Care, Utrecht, The Netherlands

${ }^{2}$ Stichting Koning Beatrix, Winterswijk, The Netherlands

${ }^{3} Z$ iekenhuis Groep Twente, Almelo, The Netherlands

${ }^{4}$ Deventer Ziekenhuis, Deventer,

The Netherlands

\begin{abstract}
PURPOSE We wanted to determine the diagnostic value of an oral prednisolone test for chronic obstructive pulmonary disorders.

METHODS Two hundred thirty-three patients with cough for longer than 14 days, without known chronic obstructive pulmonary disease (COPD) or asthma, participated in a diagnostic study in Dutch primary care between 2006 and 2009. These patients used a 14-day prednisolone test of $30 \mathrm{mg} / \mathrm{d}$ and recorded before-after bronchodilator measurements of forced expiratory volume in 1 second $\left(\mathrm{FEV}_{1}\right)$. An expert panel determined the presence or absence of COPD and asthma based on an extensive diagnostic workup. The proportion of responders to the prednisolone test (increased $\mathrm{FEV}_{1}$ exceeding $200 \mathrm{~mL}$ or $12 \%$ of baseline) per diagnosis group was compared, and the diagnostic value of the test was quantified by logistic regression and analysis of the area under the receiver operating characteristic curve (ROC area).
\end{abstract}

RESULTS In patients with COPD, 23\% (14 of 61) responded to the test; in patients with asthma 4\% (1 of 25) responded; in patients with asthma and COPD, 7\% (1 of 14) responded; and in those without asthma or COPD, 11\% (14 of 133) responded. Being a responder was, unexpectedly, associated with COPD (OR $=2.4 ; 95 \%$ confidence interval [CI], 1.1-5.2). After multivariate analysis, adjusting for age, sex, and smoking, the $\mathrm{OR}=2.0(95 \% \mathrm{Cl}, 0.8-5.0)$ and the ROC area did not increase (0.78; $95 \% \mathrm{Cl}, 0.72-0.85$ vs $0.79 ; 95 \% \mathrm{Cl}, 0.72-0.85)$.

CONCLUSION A response to a prednisolone test was suggestive of COPD, but added no diagnostic value to more easily obtainable characteristics.

Ann Fam Med 2011;9:104-109. doi.10.1370/afm.1223.

\section{INTRODUCTION}

$\mathrm{D}$ iagnosing chronic obstructive lung disorders, such as chronic obstructive pulmonary disease (COPD) and asthma, is important, because adequate treatment improves quality of life and reduces exacerbations. ${ }^{1,2}$ In primary care a diagnosis of COPD or asthma is mainly based on the results of history, physical examination, and spirometry. ${ }^{1-3}$ The interpretation of spirometry results is not straightforward, however, as there are no fixed values for (obstructive) spirometry results that confirm COPD or asthma, and results often vary with time. ${ }^{4,5}$

It has been suggested that repeating spirometry after a test treatment with oral corticosteroids might be helpful in the diagnostic workup of chronic lung disorders. A substantial improvement—or reversibility_of spirometry results, usually quantified as the forced expiratory volume in $1 \mathrm{sec}-$ ond $\left(\mathrm{FEV}_{1}\right)$, is often assumed to suggest reversible airway disorders, such as asthma, ${ }^{1,2}$ whereas a lack of improvement is considered indicative of COPD. Whether this assumption is true is unclear. There are no studies reporting the diagnostic value of the prednisolone test in patients with suspected 
asthma or COPD. Moreover, a meta-analysis showed that a positive response (a greater than 20\% increase in $\mathrm{FEV}_{1}$ ) was common after a short course of oral corticosteroids in patients with known stable COPD. ${ }^{6}$

The extent to which a test treatment of oral corticosteroids is of diagnostic value in patients with complaints suggestive of COPD or asthma remains to be established..$^{7}$ The aim of our study was to quantify the added diagnostic value of this test treatment in a large primary care population of patients with complaints of cough.

\section{METHODS}

\section{Design and Study Population}

For the present study 400 persons who were participating in a diagnostic study of COPD performed in Dutch primary care from January 2006 to May 2009 were eligible for inclusion. The protocol of this diagnostic study is described in detail elsewhere. ${ }^{8}$ Inclusion criteria were age older than 50 years and consulting a general practitioner for complaints of cough lasting 14 days or longer. Exclusion criteria were known COPD or asthma, physician-suspected pneumonia, and terminal illness. All participants gave written informed consent, and the medical ethics committee of the University Medical Centre Utrecht approved the study.

All 400 participants underwent an extensive standardized diagnostic work-up, including history, physical examination, spirometry, and whole body plethysmography. Our study focused on a subgroup of these participants who underwent a diagnostic test treatment with oral prednisolone (the prednisolone test).

\section{Test Treatment With Prednisolone}

For the prednisolone test the participants were prescribed 14 tablets of prednisolone $30 \mathrm{mg}$ to take once a day for 14 days. To prevent potential gastroduodenal toxicity, ${ }^{9}$ omeprazol $20 \mathrm{mg}$ daily was prescribed when a participant reported a history of gastrointestinal ulcer or hemorrhage or was using nonsteroidal antiinflammatory drugs, anticoagulants, or serotonin reuptake inhibitors. Participants with diabetes mellitus were instructed to measure fasting glucose after 1 week and adjust their diabetes medication, if necessary.

Participants underwent spirometry on the day before the start of the 14-day prednisolone test, as well as 14 days later. Spirometry measurements included forced vital capacity (FVC), $\mathrm{FEV}_{1}$, and the $\mathrm{FEV}_{1} / \mathrm{FVC}$ ratio after bronchodilation with $400 \mu \mathrm{g}$ of salbutamol, using multiwindow Spida 5 software combined with a SpiroUSB hand-held spirometer(ML2525; CareFusion, Chatham Maritime, Kent, United Kingdom). Participants were instructed not to use inhaled medication on the days of spirometry. We started the prednisolone test and thus the first spirometry on day 42 after participant inclusion rather than on day 1 , because spirometry results are often unreliable during episodes of cough. ${ }^{10}$ Participants were asked to consult a research physician in case of presumed side effects. After the prednisolone test, participants reported how many prednisolone tablets were used. Participants who did not undergo the prednisolone test, underwent the subsequent study tests according to the protocol as much as possible.

\section{Diagnostic Outcome}

As described elsewhere, ${ }^{8}$ the presence or absence of COPD and asthma (diagnostic outcome) was determined by an expert panel of 2 physicians, using the results of all tests - except those of the prednisolone test-according to international guidelines. ${ }^{1,2}$

The panel also determined the severity of COPD according to the criteria of the Global Initiative for Chronic Obstructive Lung Disease (GOLD), ${ }^{1}$ as well as other possible diagnoses.

A diagnosis of COPD required recurrent complaints of cough, sputum, or breathlessness, in addition to lung obstruction after bronchodilator use, defined as a lowered $\mathrm{FEV}_{1} / \mathrm{FVC}$ ratio and a concave dip in the second part of the spirometry curve. According to the GOLD guidelines, a postbronchodilator $\mathrm{FEV}_{1} / \mathrm{FVC}$ ratio of less than $70 \%$ confirms airflow limitation. ${ }^{1}$ Because the $\mathrm{FEV}_{1} / \mathrm{FVC}$ ratio physiologically decreases with age, however, COPD was not diagnosed in every participant with an $\mathrm{FEV}_{1} / \mathrm{FVC}$ ratio of less than $70 \%$. For the same reason a diagnosis of COPD was allowed without this index being less than $70 \%$ in young people. ${ }^{11} \mathrm{~A}$ history of smoking was supportive but not required for COPD. A diagnosis of asthma required recurrent episodes of wheezing, cough, or dyspnea, as well as an increase of $\mathrm{FEV}_{1}$ of more than $200 \mathrm{~mL}$ or more than $12 \%$ of baseline ${ }^{2}$ after bronchodilation. Allergy and eczema were supportive for asthma. According to the Dutch guidelines for general practitioners, both asthma and COPD could be diagnosed when $\mathrm{FEV}_{1}$ increased by more than $12 \%$ or $200 \mathrm{~mL}$ and the postbronchodilator $\mathrm{FEV}_{1} / \mathrm{FVC}$ ratio was less than $70 \%$, in combination with complaints suggestive of both disorders. ${ }^{12,13}$

\section{Data Analysis}

The response to the prednisolone test was quantified as the increase of the postbronchodilator $\mathrm{FEV}_{1}$, and expressed in milliliters and percentage of the baseline postbronchodilator $\mathrm{FEV}_{1}$. The mean increase was determined in patients with and without COPD and asthma.

The participants were categorized as responders or nonresponders to the prednisolone test. A participant was considered a responder if the increase of $\mathrm{FEV}_{1}$ exceeded $200 \mathrm{~mL}$ or $12 \%$ of the baseline value. ${ }^{14} \mathrm{We}$ 
further quantified the diagnostic value of being a responder to the prednisolone test for the presence of absence of COPD. The positive and negative predictive value and the positive and negative likelihood ratio for presence or absence of COPD of being a responder was calculated. The association between being a responder and COPD was also determined using univariate logistic regression analysis, resulting in a univariate odds ratio $(\mathrm{OR})$ with a $95 \%$ confidence interval (95\% CI). Then, using multivariate logistic regression, this association was quantified after adjustment for differences in age, sex, and current smoking, all known strong risk indicators for COPD, ${ }^{1}$ to determine the diagnostic value of the prednisolone test in addition to these characteristics. The area under the receiver operating characteristic curve (ROC area) of the multivariate model with and without the prednisolone test was quantified to determine the independent discriminative value of the prednisolone test. Analyses were performed in SPSS 15.0 (SPSS, Inc, Chicago, Illinois) and R 2.8.1. ${ }^{15}$

\section{RESULTS}

Figure 1 displays the flowchart for study participants. Of the 400 study participants who were eligible for study inclusion, 233 agreed to a diagnostic test treatment of oral prednisolone. Participants who refused to undergo the prednisolone test and those without sufficient spirometry results were excluded from the present analysis on the prednisolone test. Medical and spirometry characteristics for the study participants are displayed in Table 1. The included and excluded participants did not differ, except for pack years of smoking and baseline ratio of the $\mathrm{FEV}_{1}$ to the forced vital capacity $\left(\mathrm{FEV}_{1} / \mathrm{FVC}\right.$ ratio).
Table 1. Characteristics of Included and Excluded Participants Measured Before Prednisolone Test Treatment

\begin{tabular}{|c|c|c|c|}
\hline Characteristics & $\begin{array}{l}\text { Included } \\
N=233\end{array}$ & $\begin{array}{c}\text { Excluded } \\
N=167\end{array}$ & $P$ Value \\
\hline \multicolumn{4}{|l|}{ History } \\
\hline Age, mean (SD), y & $63(9)$ & $63(9)$ & $.7^{\mathrm{a}}$ \\
\hline Male, \% & 49 & 40 & $.1^{\mathrm{b}}$ \\
\hline Duration of cough, mean [median] (SD) & $110[42](197)$ & 89 [35] (171) & $.30^{c}$ \\
\hline Current smoker, \% & 27 & 24 & $.4^{\mathrm{b}}$ \\
\hline Pack years of smoking mean [median] (SD) & $19[10](24)$ & $12[4](20)$ & $.01^{c}$ \\
\hline Allergy for pollen or dust mite, $\%$ & 14 & 13 & $.8^{\mathrm{b}}$ \\
\hline Current use inhaled steroids, \% & 13 & 10 & $.3^{b}$ \\
\hline \multicolumn{4}{|l|}{ Spirometry ${ }^{d}$} \\
\hline $\mathrm{FEV}_{1}$, mean $(\mathrm{SD}), \mathrm{L}$ & $2.6(0.8)$ & $2.7(0.7)^{\mathrm{e}}$ & $.7^{\mathrm{a}}$ \\
\hline $\mathrm{FEV}_{1}$, predicted mean (SD), \% & $93(20)$ & $96(19)^{\mathrm{e}}$ & $.3^{\mathrm{a}}$ \\
\hline FVC, predicted mean (SD), \% & $103(19)$ & $102(19)^{\mathrm{e}}$ & $.4^{\mathrm{a}}$ \\
\hline $\mathrm{FEV}_{1} / \mathrm{FVC}$, mean (SD), \% & $73(10)$ & $76(12)^{\mathrm{e}}$ & $.004^{\mathrm{a}}$ \\
\hline \multicolumn{4}{|c|}{$\mathrm{FEV}_{1}=$ forced expiratory volume in 1 minute; $\mathrm{FVC}=$ forced vital capacity. } \\
\hline $\begin{array}{l}\text { a Independent sample } t \text { test. } \\
{ }^{\mathrm{b}} \mathrm{x}^{2} \text { Test. } \\
\text { ' Mann-Whitney } \mathrm{U} \text { test. } \\
{ }^{\mathrm{d}} \text { Postbronchodilator results. } \\
\text { e Spirometry results available for } 149 \text { of the } 167 \text { excl }\end{array}$ & ided participants. & & \\
\hline
\end{tabular}

\section{Figure 1. Flowchart of the study and the participants.}

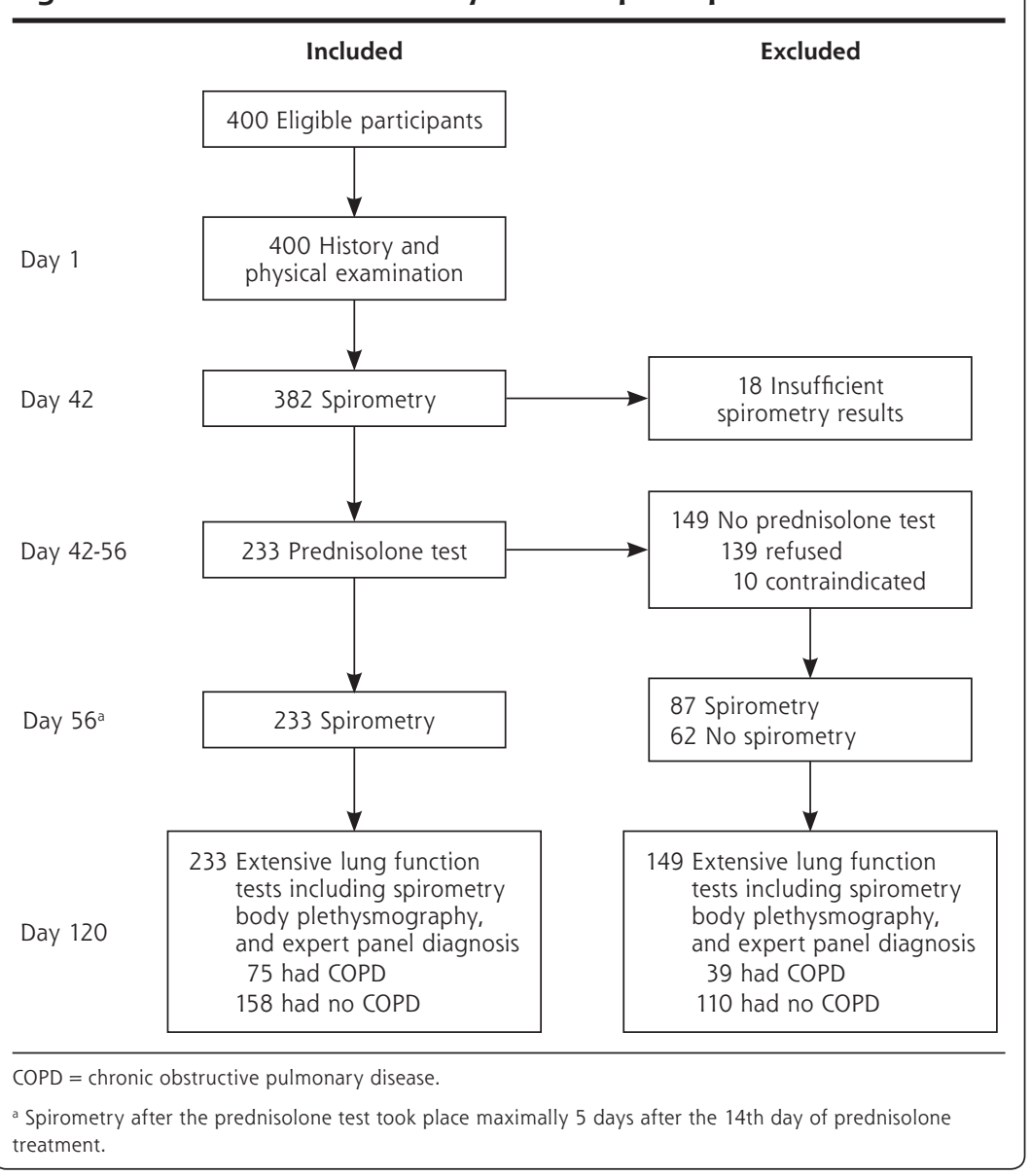




\begin{tabular}{|c|c|c|c|c|c|c|}
\hline Postbronchodilator & $\begin{array}{c}\text { Total } \\
\mathrm{N}=233\end{array}$ & $\begin{array}{l}\text { COPD } \\
n=61\end{array}$ & $\begin{array}{c}\text { Asthma } \\
n=25\end{array}$ & $\begin{array}{c}\text { COPD and } \\
\text { Asthma } \\
n=14\end{array}$ & $\begin{array}{c}\text { No COPD } \\
\text { or Asthma } \\
n=133\end{array}$ & $\begin{array}{c}P \\
\text { Value }\end{array}$ \\
\hline Increased FEV ${ }_{1}$, median (SD), \% ${ }^{a}$ & $0(9)$ & $1(10)$ & $1(4)$ & $-5(6)$ & $0(9)$ & $.01^{\mathrm{b}}$ \\
\hline Increased $\mathrm{FEV}_{1}$, median (SD), $\mathrm{mL}^{\mathrm{c}}$ & $0(190)$ & $20(230)$ & $30(130)$ & $-100(150)$ & $0(170)$ & $.01^{\mathrm{b}}$ \\
\hline Responder: $>12 \%$ or $200 \mathrm{~mL}, \mathrm{n}(\%)$ & $30(13)^{d}$ & $14(23)^{\mathrm{e}}$ & $1(4)$ & $1(7)$ & $14(11)$ & $.03^{f}$ \\
\hline \multicolumn{7}{|c|}{$\mathrm{COPD}=$ chronic obstructive pulmonary disease; $\mathrm{FEV}_{1}=$ forced expiratory volume in 1 second. } \\
\hline \multicolumn{7}{|c|}{ 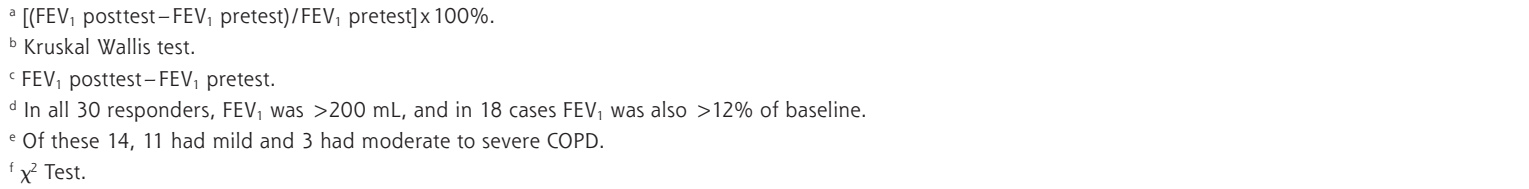 } \\
\hline
\end{tabular}

Table 3. Results of Univariate Characteristics of the Prednisolone Test for COPD and Multivariate Analysis of Responder Characteristics

\begin{tabular}{|c|c|c|c|c|c|}
\hline $\begin{array}{l}\text { Diagnostic } \\
\text { Variables }\end{array}$ & $\begin{array}{c}\text { OR } \\
(95 \% \mathrm{CI})\end{array}$ & $\begin{array}{l}\text { PPV \% } \\
(95 \% \mathrm{Cl})\end{array}$ & $\begin{array}{l}\text { NPV \% } \\
(95 \% \mathrm{CI})\end{array}$ & $\begin{array}{c}\text { LR+ } \\
(95 \% \mathrm{CI})\end{array}$ & $\begin{array}{c}\text { LR- } \\
(95 \% \mathrm{Cl})\end{array}$ \\
\hline \multicolumn{6}{|l|}{ Univariate analysis } \\
\hline Responder & $2.4(1.1-5.2)$ & $50(33-67)$ & $70(64-76)$ & $2.1(1.1-4.1)$ & $0.9(0.8-1.0)$ \\
\hline \multicolumn{6}{|l|}{ Multivariate analysis } \\
\hline Responder & $2.0(0.8-5.0)$ & - & - & - & - \\
\hline Age (per 5 y) & $1.4(1.1-1.7)$ & - & - & - & - \\
\hline Male & $2.3(1.2-4.3)$ & - & - & - & - \\
\hline Current smoking & $8.3(4.0-17.2)$ & - & - & - & - \\
\hline
\end{tabular}

and $11 \%$ in those without asthma or COPD $(P=.04)$.

Because results showed, contrary to our hypothesis, that the proportion of responders was much larger in patients with COPD than in those without COPD (Table 2), suggesting that the prednisolone test could be helpful to discriminate COPD from no COPD, we further quantified the diagnostic value of being a responder to the prednisolone test for the presence of absence of COPD. The positive predic-

Of the 233 included participants who agreed to the prednisolone test, 217 completed the test treatment of 14 tablets. Of the 16 participants using fewer than 14 tablets (average number of tablets used was 7 , minimum 2, and maximum 13), 14 did so because of side-effects, mainly gastrointestinal complaints $(\mathrm{n}=9)$ and disordered sleep $(n=4)$. The mean age of participants was 63 years, and mean duration of cough was 110 days with a median of 42 days. Excluded persons $(n=167)$ on average smoked fewer pack years and had a higher $\mathrm{FEV}_{1} / \mathrm{FVC}$ ratio than included participants (Table 1 ).

COPD was diagnosed in 61(26\%) of the 233 participants; 38 had mild disease $\left(\mathrm{FEV}_{1}\right.$ was greater than $80 \%$ of predicted), and 23 had moderate disease (FEV was $50 \%-80 \%$ of predicted). Twenty-five patients (11\%) had asthma, and 14 patients $(6 \%)$ had both (mild) COPD and asthma. The mean increase of FEV after the prednisolone test was $1 \%$ in all participants $(\mathrm{SD}=9 \%$; interquartile range $=-4 \%$ to $4 \%)$. The mean $\mathrm{FEV}_{1}$ increase per diagnosis group is shown in Table 2. The proportion of responders to the prednisolone test was $23 \%$ in patients with COPD, $4 \%$ in patients with asthma, $7 \%$ in patients with both asthma and COPD, tive value (PPV) and negative predictive value (NPV) of the prednisolone test for COPD were $50 \%$ and $70 \%$, respectively (Table 3 ). Being a responder to the prednisolone test was associated with the presence of COPD $(\mathrm{OR}=2.4 ; 95 \% \mathrm{CI}, 1.1-5.2)$. After adjustment for age, sex and current smoking, $\mathrm{OR}=2.0(95 \% \mathrm{CI}$, $0.8-5.0)$ (Table 3). The ROC area of the model including age, sex, and current smoking was $0.78(95 \% \mathrm{CI}$, $0.72-0.85$ ), and the ROC area of the model also including the prednisolone test was 0.79 (95\% CI, 0.72-0.85). The $P$ value for the difference from a reference value of 0.5 for the ROC area was $<.001$ for both models, and for the difference between the 2 models, $P=.9$.

A separate analysis among the 217 patients who completed the test treatment (intention-to-test analysis) yielded similar findings (univariate analysis, $\mathrm{OR}=2.6_{i}$ $95 \% \mathrm{CI}, 1.7-5.8$; and multivariate analysis, $\mathrm{OR}=2.3$; 95\% CI, 0.9-5.7) for the association between being a responder and the presence of COPD. An analysis of the increased FEV1 between day 42 and day 56 in 87 of the 167 participants who did not undergo the prednisolone test (Table 1 and Figure 1) showed that the proportion of responders was 9\% (2 of 23) in par- 
ticipants with COPD, and $8 \%(5$ of 64$)$ in participants without $\operatorname{COPD}(P=.9)$

\section{DISCUSSION}

We studied the response to a 14-day test treatment with oral prednisolone $30 \mathrm{mg} / \mathrm{d}$ in 233 patients complaining of cough. Being a responder was associated with COPD. After adjustment for 3 patient characteristics (age, sex, and current smoking), the multivariate association between the prednisolone test and COPD was not statistically significant; hence, the prednisolone test had no relevant added diagnostic value. Our findings were not consistent with our hypothesis that being a nonresponder is more likely in patients with COPD than with asthma.

Some possible limitations of our study should be addressed. First, 39\% of participants did not take the prednisolone test, and for only a minority was not taking the test attributable to an established contraindication for corticosteroids, such as insulin dependency or osteoporosis. Because the patients who refused did not differ substantially from those who participated, except for pack years of smoking and the baseline spirometry results, it is highly unlikely that refusal was related to the response to the prednisolone test. We therefore believe that our estimated diagnostic findings are generalizable to patients suspected of having COPD in primary care settings. Even so, 39\% of participants suspected to have COPD showed a low level of willingness to undergo the prednisolone test.

Second, one could argue that our analyses should have been limited to those patients who completed the test treatment. Because nonadherence to the full regimen is also likely to occur, however, we decided to take a pragmatic approach and report the findings for those who started the test to enhance generalizability to clinical practice.

Third, one might argue that increased $\mathrm{FEV}_{1}$ after the prednisolone test in this study might also have occurred without prednisolone, as spirometry results can vary largely within patients with pulmonary disease. ${ }^{5}$ Our results on the patients not undergoing the prednisolone test, however, suggest that the difference between the proportion of responders in participants with and without COPD who underwent the prednisolone test was indeed related to this test.

To our knowledge, the diagnostic value of a test treatment with prednisolone in patients suspected of COPD has not been reported before. In the COOPT study and in the Isolde study, a 14-day test treatment with oral prednisolone was studied in patients with known COPD with the aim to predict benefit from inhaled steroid treatment. Both studies found that the test did not predict beneficial effect of inhaled fluticasone. ${ }^{16,17}$ These results led to the recommendation not to use a test of oral corticosteroids in patients with proven COPD to decide on prescription of long-term inhaled steroids. ${ }^{1}$

In our study, the relatively high proportion of responders in participants with COPD could be related to ongoing eosinophil (or other corticosteroidsensitive) inflammation, ${ }^{18,19}$ illustrated a subgroup of patients with COPD that respond well to long-term inhaled corticosteroids. ${ }^{20,21}$ Our findings are in line with the understanding that COPD is a heterogenic disorder, characterized by airflow obstruction that is not fully reversible and an abnormal inflammatory airway response. ${ }^{1,22}$ In analogy to the improvement or reversibility of spirometric results after a prednisolone test, reversibility after inhaled bronchodilators is currently recognized as a common feature of COPD, whereas earlier a lack of reversibility was considered typical for COPD. ${ }^{21,23-27}$

The widely acknowledged underdiagnosis and misdiagnosis of chronic lung disorders in primary care underline a need for more consistent criteria than expert opinion to define chronic lung disorders. Moreover, and especially in elderly patients, asthma and COPD often overlap, usually in patients with asthma who are exposed to cigarette smoke or other noxious gases, who develop a COPD-like obstructive spirometry pattern. ${ }^{2,28}$ Extensive history taking is currently acknowledged as the main tool to differentiate asthma from COPD, and questionnaires were recently developed for this purpose. ${ }^{29,30}$

Being a responder to a 14-day test treatment with oral prednisolone was suggestive of COPD, contrary to earlier assumptions, but had no clear value for diagnosing or excluding COPD in addition to more easily obtainable diagnostic information. In view of the unwillingness of many patients to undergo the prednisolone test, we do not recommend this test in the diagnostic workup when chronic obstructive lung disorders are suspected.

To read or post commentaries in response to this article, see it online at http://www.annfammed.org/cgi/content/full/9/2/104.

Key words: COPD; asthma; diagnostic tests, routine; cough; corticosteroids

Submitted May 25, 2010; submitted, revised, October 25, 2010; accepted November 5, 2010.

Financial support: This work was funded by the Netherlands Organisation for Health Research and Development (ZonMw), grant No. 945-04015; and research grants from GlaxoSmithKline, Boehringer-Ingelheim, and Pfizer.

Disclaimer: The study sponsors had no involvement in the study 
design, the collection, analysis, and interpretation of the data, the writing of the report, or in the decision to submit the paper for publication.

Acknowledgments: We gratefully acknowledge all participating patients, general practitioners, and other health care professionals who contributed to the study. Chantalle van de Pas and Nanoesjka van Gorcum, research physicians, performed spirometry measurements.

\section{References}

1. Rabe KF, Hurd S, Anzueto A, et al. Global strategy for the diagnosis, management, and prevention of chronic obstructive pulmonary disease: GOLD executive summary. Am J Respir Crit Care Med. 2007; 176(6):532-555.

2. Global Strategy for Asthma Management and Prevention, Global Initiative for Asthma (GINA). http://www.ginasthma org 2010.

3. Levy ML, Quanjer PH, Booker R, Cooper BG, Holmes S, Small I. Diagnostic spirometry in primary care: Proposed standards for general practice compliant with American Thoracic Society and European Respiratory Society recommendations. Prim Care Respir J. 2009;18(3):130-147

4. Pennock BE, Rogers RM, McCaffree DR. Changes in measured spirometric indices. What is significant? Chest. 1981;80(1):97-99.

5. Rozas CJ, Goldman AL. Daily spirometric variability: normal subjects and subjects with chronic bronchitis with and without airflow obstruction. Arch Intern Med. 1982;142(7):1287-1291.

6. Callahan CM, Dittus RS, Katz BP. Oral Corticosteroid therapy for patients with stable chronic obstructive pulmonary disease. Ann Intern Med. 1991;114(3):216-223.

7. Borrill Z, Houghton C, Sullivan PJ, Sestini P. Retrospective analysis of evidence base for tests used in diagnosis and monitoring of disease in respiratory medicine. BMJ. 2003;327(7424):1136-1138.

8. Broekhuizen BD, Sachs AP, Hoes AW, et al. Undetected chronic obstructive pulmonary disease and asthma in people over 50 years with persistent cough. Br J Gen Pract. 2010;60(576):489-494.

9. Hernandez-Diaz S, Rodriguez LA. Steroids and risk of upper gastrointestinal complications. Am J Epidemiol. 2001;153(11):1089-1093.

10. Williamson HA Jr. Pulmonary function tests in acute bronchitis: evidence for reversible airway obstruction. J Fam Pract. 1987;25(3): 251-256.

11. Roberts SD, Farber MO, Knox KS, et al. FEV 1 /FVC ratio of $70 \%$ misclassifies patients with obstruction at the extremes of age. Chest. 2006;130(1):200-206

12. Geijer RM, Smeele IJ, Goudswaard AN. [Summary of the practice guideline 'Asthma in adults' (2nd revision) from the Dutch College of General Practitioners]. Ned Tijdschr Geneeskd. 2008;152(20): 1146-1150.

13. Smeele IJ, van Weel C, Van Schayck CP, et al. NHG-standaard COPD. Huisarts Wet. 2007;50(8):362-379.
14. Pellegrino R, Viegi G, Brusasco V, et al. Interpretative strategies for lung function tests. Eur Respir J. 2005;26(5):948-968.

15. R: A Language and Environment for Statistical Computing, R Development Core Team. R Vienna, Austria: Foundation for Statistical Computing; 2008.

16. Burge PS, Calverley PM, Jones PW, Spencer S, Anderson JA. Prednisolone response in patients with chronic obstructive pulmonary disease: results from the ISOLDE study. Thorax. 2003;58(8):654-658.

17. Chavannes NH, Schermer T, Wouters EF, et al. Predictive value and utility of oral steroid testing for treatment of COPD in primary care: the COOPT study. Int J COPD. 2009(4);2009.

18. Rutgers SR, Postma DS, ten Hacken NHT, et al. Ongoing airway inflammation in patients with COPD who do not currently smoke. Thorax. 2000;55(1):12-18.

19. Lapperre TS, Snoeck-Stroband JB, Gosman MM, et al. Dissociation of lung function and airway inflammation in chronic obstructive pulmonary disease. Am J Respir Crit Care Med. 2004;170(5):499-504.

20. Brightling CE, Monteiro W, Ward R, et al. Sputum eosinophilia and short-term response to prednisolone in chronic obstructive pulmonary disease: a randomised controlled trial. Lancet. 2000;356 (9240):1480-1485.

21. Beasley R, Weatherall M, Travers J, Shirtcliffe P. Time to define the disorders of the syndrome of COPD. Lancet. 2009;374(9691):670-672.

22. Wedzicha JA. The heterogeneity of chronic obstructive pulmonary disease. Thorax. 2000;55(8):631-632.

23. Calverley PM, Burge PS, Spencer S, Anderson JA, Jones PW. Bronchodilator reversibility testing in chronic obstructive pulmonary disease. Thorax. 2003;58(8):659-664.

24. Tashkin DP, Celli B, Decramer M, et al. Bronchodilator responsiveness in patients with COPD. Eur Respir J. 2008;31(4):742-750.

25. Kesten S, Rebuck AS. Is the short-term response to inhaled betaadrenergic agonist sensitive or specific for distinguishing between asthma and COPD? Chest. 1994;105(4):1042-1045.

26. Nisar M, Walshaw M, Earis JE, Pearson MG, Calverley PM. Assessment of reversibility of airway obstruction in patients with chronic obstructive airways disease. Thorax. 1990;45(3):190-194

27. Gross NJ. COPD: a disease of reversible air-flow obstruction. Am Rev Respir Dis. 1986;133(5):725-726.

28. Gibson PG, Simpson JL. The overlap syndrome of asthma and COPD: what are its features and how important is it? Thorax. 2009; 64(8):728-735.

29. Tinkelman DG, Price DB, Nordyke RJ, et al. Symptom-based questionnaire for differentiating COPD and asthma. Respiration. 2006; 73(3):296-305.

30. Price DB, Tinkelman DG, Halbert RJ, et al. Symptom-based questionnaire for identifying COPD in smokers. Respiration. 2006;73(3): 285-295. 